\title{
The Electronic Revolution and the Evolving Role of the Academic Reference Librarian
}

by Deborah Stanley and Natasha Lyandres

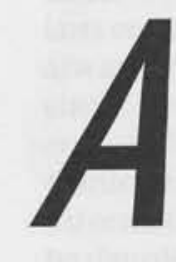

ssisting and advising have always been central to the role of the reference librarian. The nature of reference work, however, has evolved over recent years as a result of the proliferation of electronic resources and their impact on access to information. More than ever before, reference librarians spend their time at the reference desk guiding students through myriad electronic resources and the technical skills needed to access them. At this point, most students begin their college careers with some degree of computer literacy, but lack information literacy - the ability to find the best information and to evaluate it effectively. Access to the Internet and other electronic information sources affords these computer-literate students a valued sense of independence and privacy in information seeking, with the result that they often do not see the need to approach librarians for assistance.

An increasingly important issue for academic libraries in general and for reference departments in particular, therefore, is how to provide academic users with both reference assistance and the necessary skills to find, use, and evaluate information on their own. The purpose of this article is to identify and discuss effective ways to empower our increasingly independent users through creative instruction methods and innovative reference services.

\section{Reference Is Instruction}

In the latest edition of his Introduction to Reference Work, Bill Katz discusses the increasing complexity of the reference librarian's role and defines the continued growth in demand for instruction in the use of resources as one of the dominant trends that affects reference services. ${ }^{1}$ Most reference work has a considerable teaching component, as it involves not only answering questions but also providing advice in determining the most effective search strategy for a particular individual. Indeed, studies of the quality of reference service emphasize "the importance of the teaching/learning component of reference work and identify facilitating user independence as a primary function of reference service." 2 Such impromptu instruction is, therefore, a vital aspect of reference service in an academic library and contributes to the student's learning experience and educational development.

Moreover, reference assistance becomes even more critical as technology changes information-seeking behavior. As library collections become more accessible via the Internet, the number of virtual users, or users who wish to access information independently, will undoubtedly continue to grow. Ann Jensen and Julie Sih, in an article on using electronic mail to deliver instruction, ${ }^{3}$ argue that in-depth training programs to prepare patrons for times when they are left to their own devices are the most logical alternative to 24 hour reference services.

In 1989, the American Library Association defined the information literate as "people prepared for lifelong learning, because they can always find the information needed for any task or decision at hand." 4 We believe that reference librarians must reevaluate their instructional and teaching methods in order to empower students with basic information knowledge and skills.

\section{Creative Instruction}

\section{Cooperative Teaching}

It is our experience that traditional one-hour "canned" presentations on how to conduct library research do little to help reduce the gap between students and the library. The literature reveals that such sessions often tend to be perceived by teaching faculty and students as "passive learning experiences." ${ }^{15}$ Although most traditional presentations do provide a general overview of library information resources and services, they do not teach stu- 
dents how to use and evaluate information for a particular project. It has been pointed out by teaching faculty that actively incorporating information and critical thinking skills into specific assignments, rather than offering separate information literacy courses, is the most effective way to help students develop these abilities. ${ }^{6}$

Should the teaching of these critical information skills, therefore, be a responsibility of teaching faculty or of librarians? In his article, "Bridging the Gap Between the Student and the Library," Philip J. Egan indicates that "help should come from someone who is sympathetic, who knows the research task assigned, and who will assist the student in the use of complex bibliographic tools. Most important, this person should help students link up their research with the requirements of the assignment. This person is the teacher." 7

Through our personal experience and from professional discussions, however, it seems that many teaching faculty find it increasingly difficult to keep up with new library resources and may also lack the sophisticated searching skills necessary to assist students. In a recent focus group session with teaching faculty at East Carolina University, many instructors expressed concern that they did not possess the knowledge or skills to utilize new library resources and therefore felt that both they and their students needed assistance from librarians in using these resources. We believe librarians should be more proactive in developing contacts with teaching faculty and encouraging cooperation in order to help students achieve the required information literacy level. If teaching faculty value our knowledge and expertise, we can become effective partners. Although cooperative teaching projects are relatively rare, those that have been implemented show very positive results. For example, Dennis Isbell and Dorothy Broaddus ${ }^{8}$ describe the teaching partnership experiment between a librarian and a professor of English at Arizona State University West in which they taught research strategy, evaluation of information, and composition. The authors indicate that the cooperative approach offers an opportunity for students to view research and writing as a continuum, allows time for indepth evaluation of reference and research sources, and provides an interactive forum for teaching critical thinking skills.

Working in partnership with teaching faculty is an effective way not only to offer training but also to convince patrons of the need for it. Patrons who are tenacious in seeking information or have a specialized subject knowledge are often highly motivated to seek the training that will allow them to be as sophisticated as possible in searching electronic databases. Others, notably undergraduate students, may not be as interested. They are often just as enthusiastic when it comes to operating in the electronic environment, but less cognizant of the need for information skills; they often assume that if they know how to enter keywords into a Web search engine, they know all they need to know about finding information. By working with faculty and incorporating information skills into the curriculum, librarians can show students that, by developing these skills and an awareness of resources, they can find more useful information more quickly. This enhances the image of the librarian as someone who has relevant and interesting knowledge to share, increasing the likelihood that students will seek advice from reference librarians in the future.

In fact, librarians should establish cooperative alliances not only with teaching faculty, but also with others on campus, specifically computing specialists. The explosion of electronic information has blurred the lines between computing and library skills, with the result that sometimes librarians teach students the technical aspects of using computers to find information, while computing specialists may find themselves called upon to teach the evaluation of information content.

\section{... reference librarians must reevaluate their instructional and teaching methods in order to empower our students with basic information knowledge and skills.}

\section{Electronic Teaching}

With large class sizes, lack of student enthusiasm for a one-time presentation on library skills, and the opportunities offered by the Internet, increasing numbers of reference librarians are taking advantage of the interactive, adaptable nature of the Internet and its possibilities for offering instruction through self-directed, self-paced online tutorials. "The advantages of offering instruction over the Web include its learner-centered environment, global access, easy update procedures, and cross-platform use." 9

In response to the fact that providing orientation to at least 6,000 new students at their West Lafayette campus each year was a practical impossibility, librarians at Purdue University created an interactive World Wide Web information literacy module named PLUTO (Purdue Libraries Undergraduate Tutorial Online). ${ }^{10}$ They took care to design the module to fulfill the learning objectives determined by classroom instructors, student government organizations, and Purdue librarians. Those objectives - teaching students to define and formulate keyword searches; retrieving information on a topic from THOR, the online system; and locating information from THOR within the Purdue Libraries System provided the structure for the module. One of the main factors in the success of the project was the involvement of students and teaching faculty in its design from the earliest stages.

Librarians from ten Utah colleges and universities offered Internet Navigator, a "one credit-hour introductory course intended to emphasize information literacy rather than Internet mechanics."11 Students and instructors communicated via e-mail and also used a mailing list as a distributed teaching method. Students enjoyed the delivery method and appreciated the self-paced nature and hands-on aspects of the course. They also found it useful to have all course materials available at all times for review. There are, of course, negative aspects to teaching information skills virtually, most notably the lack of personal contact with students, especially as there will always be a disparity among students in terms of their motivation and ability to work independently. The ability to offer credit courses or Web-based guides to research and resources as online tutorials, however, is surely a positive development and a useful addition to the instruction librarian's repertoire. This 
type of instruction provides a unique opportunity for students to learn about information resources regardless of the time of day or their physical location.

There is also a need for resourcebased instruction for students and faculty who wish to learn about advanced search techniques. Librarians can meet these needs through informal drop-in sessions. Sometimes, however, faculty and graduate students lack the time to attend classes in the library or may not wish to acknowledge in front of others that they need training. For this reason, engineering librarians at two campuses of the University of California, UC-San Diego and UC-Berkeley, developed an instruction program delivered via electronic mail. They devised six short, self-paced tutorials on INSPEC, a major research database in the fields of physics, computing, and electronics. The use of e-mail to deliver training gave users privacy and convenience. The course was offered on an enrollment basis to avoid bombarding faculty with unwanted e-mail. Those who enrolled received one lesson per week for six weeks. Users overwhelmingly found this a convenient way to receive training and were pleased that they also could keep the e-mail tutorials to refer to later. This project had additional benefits: it could be implemented each semester with little additional work for the librarians and it opened lines of communication with faculty. The librarians involved in the project felt that it was a success: "By providing these tutorials in addition to more traditional instructional methods, we are making a powerful statement to our patrons about the library's attentiveness to their needs." 12

\section{Innovative Reference Services}

As those seeking information increasingly are able to access it remotely, they are faced with an often bewildering array of options, technical problems, and search strategy decisions. It is imperative for libraries and for their constituencies that reference service be as widely available as possible. Technology will allow increased access in various ways: users will be able to contact librarians by telephone, electronic mail, or by filling out reference requests on the Web; librarians will be able to provide services such as catalogs of Internet resources and guides to searching, which can be accessed by patrons around the clock. Face-to-face reference service will move out of the library to some extent, and closer to patrons.
Reference Services Outside the Library Networked information increasingly affords librarians the capability to provide reference services from remote locations. In an article on the changing roles of reference librarians, Julie Kelly and Kathryn Robbins argue that "as more of the commonly-used reference tools become available in electronic forms, the reference desk could migrate to any location where users have access to the librarian and he or she has access to a terminal."13 A librarian could have an office or a desk in one or more academic departments, scheduling certain hours of the week for reference questions and one-on-one instruction on database searching. Where a subjectspecific library is housed in the same building as the academic departments it serves, this will not be necessary. Where there is one central library on campus, however, this type of service could encourage students and faculty to consult a librarian and show that the library is taking the needs of its patrons seriously. There is also the opportunity for co-operation with our colleagues in campus computing services as librarians go out to computing laboratories across campus and offer information content to complement the technological support already provided.

\section{E-Mail Reference Services}

Along with experimenting with the physical location of reference services, libraries also should continue to take advantage of information technology in order to provide assistance to remote users. In addition to providing reference services by telephone, librarians are now utilizing electronic mail, the Web, and videoconferencing technology.

With widespread access, electronic mail has potential as an important delivery method for reference service. It is an issue that is debated frequently within the profession. Libraries of different types often have similar experiences with e-mail reference. There is the initial worry that it will generate more questions than the staff can handle, but in practice this does not happen. Usually demand is fairly light and messages are checked once or twice a day by designated staff. E-mail reference questions can be forwarded to the person with the most knowledge of the subject, even if that person is not in the reference department or is away from the library at the time the request is received. Because it is not a real-time exchange between the patron and the librarian, however, it can become timeconsuming if the patron does not provide sufficient information about what he or she actually wants. The librarian then has to follow up with additional questions. As with traditional reference there is a teaching element, with librarians explaining to patrons how to use the resources to which they direct them.

The experience of the Internet Public Library (IPL) electronic mail reference service can provide useful guidance. ${ }^{14}$ The IPL found that it was able to elicit more useful information in the initial inquiry by asking the patron to complete a specially-designed Webbased form. It also found that the number of questions received related to the amount of publicity recently given to the IPL. Publicity seems to be a key issue in terms of use of e-mail reference. The difficulty in promoting it widely, however, is that libraries may not be able to cope with the ensuing demand. Such resource issues will come increasingly to the fore as libraries develop additional electronic services.

\section{Exploring Network Technologies}

Alongside the ubiquitous telephone reference and the fairly widespread email reference, there are also other, more unusual, attempts to provide reference service to remote users. One interesting experiment took place at the University of Texas at Austin in 1992. Software mounted on designated public computers in remote campus locations enabled librarians, at the user's request, to connect into database search sessions and intervene. ${ }^{15}$ This pilot project used a networked CDROM of U.S. government information. The software allowed the user's screen to be visible on the librarian's computer. Both the patron and the librar- 
ian could use his or her own mouse and keyboard to navigate the search screen, although the actual operations on the database were performed by the patron's workstation. The librarian could see what the patron was doing and offer advice and instruction by telephone. Although searches were completed successfully with intervention there were practical limitations, such as the need for the patron to use a computer with the appropriate software and to have access to a telephone. Use of the service was relatively light, and depended on students' motivation and their level of comfort with the interpersonal aspects of the technology. The outcome of this project demonstrates that, although the fundamental technologies are in place to provide this type of service, it is another issue altogether as to whether patrons are psychologically ready to use it.

At North Carolina State University, librarians initiated a project called "See You See a Librarian" in 1996, using CUSeeMe, free desktop videoconferencing software. ${ }^{16}$ With this software and digital cameras, individuals from around the world conducted real-time conversations. Although initial interest and involvement were high, response dwindled by the third stage, which was the discussion using this technology to field reference questions. The University of Michigan has used this same technology since 1995. Reference librarians establish a link with libraries in students' residence halls and use the video technology to check for walk-in patrons, listen for the phone, and check the computer monitor. The library sees this program as a chance to expand reference service without increasing staff rather than as a way to alter reference service significantly. ${ }^{17}$

Although many of these attempts to provide service to remote patrons have not experienced high use, they do nevertheless offer patrons other options in accessing reference service. It is possible, as people become more comfortable with videoconferencing and other technologies, that such projects will expand. It would seem that what is important at this stage is to encourage the use of remote reference service. This can be done by instruction and enhanced publicity, by keeping abreast of technological developments and experimenting with imaginative pilot projects, and by showing patrons that the library is responsive to their needs.

\section{Organizing Electronic Information}

Building on their traditional skills, many librarians are selecting, organizing, and making accessible the most appropriate Internet sources for their users. Kelly and Robbins advocate, as do many others, that librarians should "use their skills in both organization of information and sensitivity to user needs to work on the development of more powerful navigation tools such as intelligent browsers, gateways, catalogs of resources or other tools yet to be developed."18 Although commercial services such as Yahoo provide catalogs of resources, and Internet service providers such as America Online create marketable virtual environments for their customers, libraries have a vital role in selecting and organizing resources of particular interest to different sectors of their communities. This allows us to fulfill our traditional role of providing patrons with the most appropriate and useful resources, a role that is more important than ever given the overwhelming amount of electronic information now available. One of the most successful and well-developed examples is Infomine ( $h t t p: / / l i b$ www.ucr.edu), based at the University of California, Riverside. Infomine provides a series of subject-related catalogs of Internet sites, guides, and finding tools. A librarian selects each resource and provides a detailed record with descriptors, which enables patrons to search the database by keyword. It is just one example among a number of popular and successful gateways, including the Argus Clearinghouse subject index of Internet guides (http://www. clearinghouse.net) initiated at the University of Michigan, and Iowa State's CyberStacks catalog of Internet resources classified according to the Library of Congress classification scheme. In addition, many libraries now have home pages with links to ready reference and subject-specific resources, Internet guides, and resources available on the library's own network.

Increasingly, the virtual environment, in the form of the library's home page, provides the gateway to both virtual and traditional library resources. Libraries must continue to work towards providing simplicity and consistency in terms of interfaces to these resources. Z39.50, the ISO standard for information retrieval using client/ server architecture, allows users to connect to remote databases and to search them using the same search and navigation methods and with very similar screen layout. As confusion over the different search interfaces provided by different database vendors is one of the major sources of reference questions at present, libraries, vendors, and others involved in information provision must work towards increased standardization using Z39.50. This would be one of the most significant and beneficial developments in improving the success rate of searching by independent information seekers.

In an article on the role of the "virtual librarian," Cherrie Noble also highlights the metadata movement, an important and growing trend. She describes metadata as "essentially data about data" and metatagging as "the use of a descriptive field or tag."19 Metatags are used to create a descriptive record for Internet resources. They are a less detailed alternative to traditional bibliographic records. Users cannot see metadata, but search engines use it to rank sites in relevancy lists. Standards are currently being developed for metadata. Noble cites Amanda $\mathrm{Xu}$, a serials cataloger at MIT, who believes that, as Internet resources will increasingly have metadata already attached, the library's Web site will become the logical gateway for accessing these resources.

\section{Organizational Ethos}

Jennifer Mendelsohn identifies the major factors that contribute to quality reference service as willingness, knowledge, morale, and time. ${ }^{20}$ Certainly, knowledge contributes to morale and to willingness in helping patrons; librarians need to dedicate time to keeping up-to-date with new technologies and electronic resources if they are to do their jobs effectively. "The concept of knowledge renewal and growth is an important one. The links between knowledge, morale and willingness must be recognized." 21 It is not enough for librarians to receive training; they must take an active role in their own development of skills and knowledge in the virtual environment, adopting a life-long learning approach. The library as a whole also needs to adopt such an attitude. Libraries must develop as learning organizations, encouraging the professional development of their staffs, both in new skills and new perspectives.

\section{Conclusion}

Through creative instruction and innovative reference services, reference librarians can contribute to students' development of information skills that 
will remain relevant even as technology continues to evolve. To achieve this goal, it is vital that librarians take a proactive role in forming cooperative partnerships with campus colleagues, particularly with teaching faculty and systems specialists.

Sweeping technological changes have had a dramatic impact both on the way reference librarians work and on the information-seeking behavior and expectations of academic library users. Although this may be perceived as a threat to the status of the academic library as the central access point to information, we believe that those same technological developments also afford a greater opportunity than ever before to make academic libraries exciting, friendly, and relevant.

\section{References:}

1 William A. Katz, Introduction to Reference Work, 7 th ed. vol.1 (New York: McGraw-Hill, 1997), xvi.

2 Jennifer Mendelsohn, "Perspectives on Quality Reference Service in an Academic Library: a Qualitative Study," RQ 36 (Summer 1997): 545.

3 Ann Jensen and Julie Sih, "Using EMail and the Internet to Teach Users at Their Desktops," Online 19 (Sept./Oct. 1995): 82-86.

4 American Library Association. Presi- dential Committee on Information Literacy. Final Report. (Chicago: American Library Association, 1989), 1.

5 Vivian Parker Makosky, "Teaching Psychology in the Information Age," Teaching Psychology 12 (February 1985): 23-26

6 Philip J. Egan, "Bridging the Gap Between the Student and the Library," College Teaching 40, 2 (Spring 1992): 67-70.

7 Ibid.

8 Dennis Isbell and Dorothy Broaddus, "Teaching Writing and Research as Inseparable: A Faculty-Librarian Teaching Team," Reference Services Review 23 (Winter 1995): 51-62.

9 Ann Margaret Scholz, Richard Cary Kerr, and Samuel Keith Brown, "PLUTO: Interactive Instruction on the Web," College and Research Libraries News 57, 6 (June 1996): 346.

10 Ibid., 346-349.

11 Carol Hansen and Nancy Lombardo, "Toward the Virtual University: Collaborative Development of a Web-based Course," Research Strategies 15 (Spring 1997): 68-79.

12 Jensen, 84-86.

13 Julia Kelly and Kathryn Robbins, "Changing Roles for Reference Librarians," in Managing Change in Academic Libraries, ed. Joseph J. Branin (New York: Haworth Press, 1996): 115.

14 Nettie Lagace and Michael
McClennen, "Questions and Quirks: Managing an Internet-based Distributed Reference Service," Computers in Libraries 18 (February 1998): 24-27.

15 Harold Billings, et al., "Remote Reference Assistance for Electronic Information Resources Over Networked Workstations," Library Hi Tech 12, 1 (1994): 77-86.

16 "Virtual Service" American Libraries 28, 1 (January 1997): 44-45.

17 Ibid.

18 Kelly, 114.

19 Cherrie Noble, "Reflecting on Our Future," Computers in Libraries 18 (February 1998): 53.

20 Mendelsohn.

21 Ibid., 555.

\section{Thank You to NCLA}

Contributing Members:

David S. Ferriero,

Duke University

Dr. Benjamin F. Speller,. Jr., North Carolina Central University

SOLINET

Tom Broadfoot, Broadfoot's Publishing Company

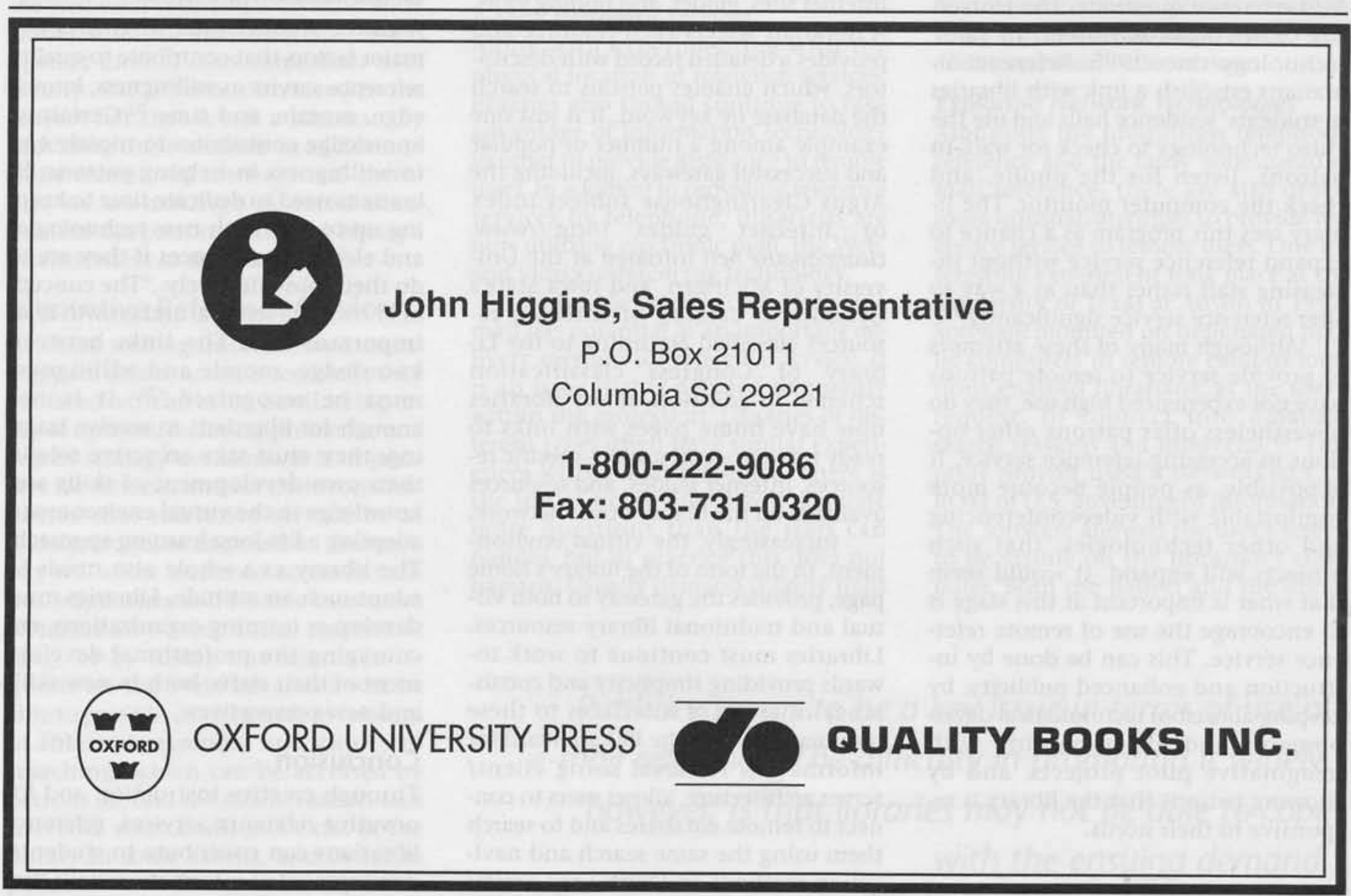

